\title{
Consistency analysis of sand cone and nuclear method results in compacted soils
}

Ismail Zorluer (Main and Corresponding Author)

Afyon Kocatepe University, Department of Civil Engineering

ANS Campus 03200 Afyonkarahisar (Turkey)

izorluer@aku.edu.tr

https://orcid.org/0000-0001-5017-084X

Yillmaz Icaga

Afyon Kocatepe University, Department of Civil Engineering

ANS Campus 03200 Afyonkarahisar (Turkey)

yıcaga@aku.edu.tr

https://orcid.org/0000-0001-9347-4683

\section{Suleyman Gucek}

Afyon Kocatepe University, Department of Civil Engineering

ANS Campus 03200 Afyonkarahisar (Turkey)

sgucek@aku.edu.tr

https://orcid.org/0000-0002-4839-1851

\section{Erdinc Dundar}

Afyon Kocatepe University, Department of Mathematics

ANS Campus 03200 Afyonkarahisar (Turkey)

edundar@aku.edu.tr

https://orcid.org/0000-0002-0545-7486

Manuscript Code: 14060

Date of Acceptance/Reception: 23.09.2020/22.09.2019

DOI: 10.7764/RDLC.19.3.431

\section{Abstract}

In this study, the ratio of compaction was determined by sand cone and nuclear test methods performed in the same place. The normal distribution fitness of the compaction percentiles was tested by the Anderson-Darling test and normal distribution was normalized by subjecting the unsuitable Water Content values to Jonson transformation. Findings the results obtained with the nuclear method reveal that both methods are consistent with each other in terms of mean data, with lower and more variables in the Sand Cone method. It is recommended to test the consistency of the results obtained by the nuclear method. Also, because of the rapid results, statistical model has been investigated for adapting the results of nuclear method to the sand cone method. For this purpose, regression analysis and artificial neural network models were investigated; artificial neural networks were seen to provide successful predictions inside of the found models.

Key words: Sand cone, Nuclear method, Water content, Soil compaction method, compaction ratio.

As a building material, the soil is used to make earthfill structures. In order to create the earthfill structure, the soil must be sufficiently compacted. The purpose of compaction is to increase strength, reduce settlement, reduce permeability, control swelling and liquefaction, and so on. To achieve one or more of these purposes, the soil is laid in layers and the compaction is applied to each layer. The sufficiency of compaction is determined by the compaction ratio. The compaction ratio is determined by the ratio of the dry density measured in the field to the dry density determined in the laboratory.

There are several experimental methods used to determine the compaction ratio. The measurement is performed by using one of these methods according to the features of the soil. Methods such as sand cone are in the destructive test class because excavation is applied at the measurement site. It is also time-consuming to determine the water content. Non-destructive methods come to the forefront instead of sand cone. The nuclear method determines the water content and density of the layer by means of the radioactive material in the device. There are also time domain reflectometry (TDR) methods and electromagnetic methods (Chanyong et al., 2016; Chai \& Wang 2014; Sawangsuriya, 2012). These methods are preferable methods for quick results. 
However, there are doubts about the reliability of these methods (Altun et al., 2008; Altun et al., 2007). Because the results of different in situ tests in the same area of the compacted layer give different values. Therefore, some approaches have been developed to more accurately determine the density and water content of the soil. In a study by Mahmoud Hassanlourad et al. (2017), the polynomial neural network (NN) used the indirect density of compressed soils to estimate the dry density of compressed soils in relation to P-wave velocity (Vp), moisture content ( $w$ ) and plasticity index (PI) and fine-grained particles. To determine the performance of the proposed model, a statistical comparison was made between the experimental and predicted values. An equation has been proposed using multiple regression analysis.

There are studies evaluating the results of two in situ tests in the same field with comparative analysis. Altun et al. (2007) analyzed the data obtained from the sand cone and nuclear test by various statistical methods. The results of these tests performed in the same area were compared. The results were evaluated with statistical analysis. The significance of the relationships between the main statistical parameters of the experimental data and the linear relations between the parameters were analyzed. These methods emphasized the importance of statistics in their relations. In another study, Altun et al. (2008), sand cone and nuclear test in the same area, unit weight, water content and change of compaction ratio values were examined and compared. The data at hand were first subjected to statistical analyses. Next, several techniques were used to identify the correlation between the results of the 2 tests. Finally, susceptibility and reliability concepts were considered in evaluating the combined usage of the tests in civil engineering practice.

In this study, dry unit weights measured by nuclear method and by sand cone in the same point, were evaluated statistically. The compaction ratios of the soil under the buildings were calculated and the conformity check of the calculated values with the normal distribution was tested by the Anderson-Darling test. Correlations between the data were obtained and Regression and Artificial Neural Network models were developed to make the transition from the results obtained with the nuclear test to the sand cone test.

Materials and methods

\section{Experimental site features}

For compaction ratio, measurements were made in base fills under the mill and cement silo structures of a cement plant. Under the foundations of these structures, coarse grained material was laid for improvement. The coarse grained soil is a well-graded sand and gravel (SW-GW) type soil. Then roller compaction was applied to the coarse grained layers laid under the buildings. Two different tests were conducted at the same point to determine the compaction ratio of these layers. The tests were conducted in 8 locations and 32 different points. 4 different points were determined in every location.

Compaction ratio is the ratio of dry density measured in the field to the maximum dry density determined in the laboratory. To determine Dry densities of layers, the density and water content of the compacted layers were measured by sand cone and nuclear device. Firstly, the measurement was performed with nuclear device as it is a non-destructive device. Then the measurement was performed with sand cone device in the point near 8-10 cm of the Nuclear Device test point.

\section{Sand cone method}

The sand cone device consists of a plastic jar with a metal cone attached at its top (Figure 1). The jar is filled with uniform dry sand. The combined weight of the jar, the cone, and the sand filling the jar is determined. In the compacted soil layer, a hole of $20-25 \mathrm{~cm}$ depth is excavated with the help of the cone plate; the material extracted from the hole is weighted. In addition, from excavated soil the sample are taken to determine the water content of the material. The excavated hole is filled with sand which is known of density. The volume of the hole is determined by the help of this sand. Then the unit weight and dry unit weight of the layer are calculated. This test is performed according to TS 19001(2006). Figure 1 shows cross section of sand cone test equipment.

\section{Nuclear method}

The nuclear density meter is used for determining the dry unit weight of compacted soil layer. This device is quick and fairly way of determining density and moisture content. Density Test is made according to ASTM 6938-17a (2003). The device uses a radioactive isotope source (Cesium 137) at ground surface (backscatter) or from a probe placed into the soil (direct transmission). The isotope gives off Gamma rays that radiate back to the meter's detectors on the bottom 
of the unit. Dense soil absorbs more radiation than loose soil and the readings reflect overall density. Figure 2 shows nuclear density device.

Figure 1. Cross section of sand cone test equipment. Source: ground engineering service.

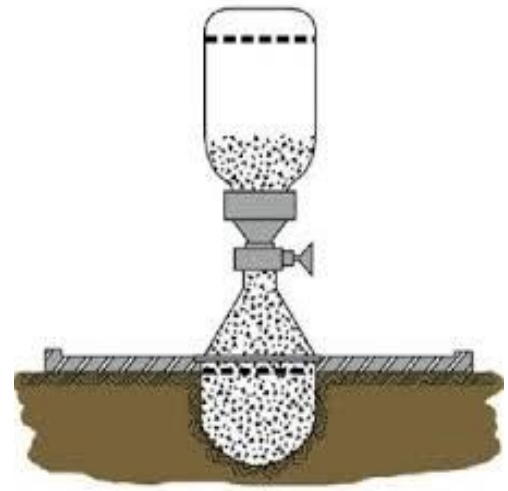

Figure 2. Nuclear density measuring device. Source: EPA.

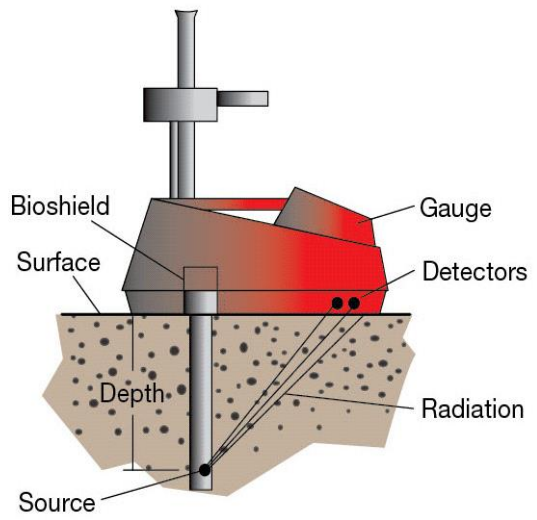

\section{The Sand Cone and the Nuclear Density Tests Results}

The mean values of the sand cone test and the nuclear density test results in 8 locations and 32 points are given in Table 1 , Figure 3 , and 4 , respectively.

Table 1. The mean values of the sand cone and nuclear density tests. Source: Self-elaboration.

\begin{tabular}{ccccc}
\hline Location & C_SC Means & C_Nuclear Means & W_SC Means & W_Nuclear Means \\
\hline 1 & 97.68 & 104.49 & 1.48 & 6.82 \\
2 & 98.70 & 104.26 & 1.58 & 5.56 \\
3 & 100.20 & 103.92 & 2.13 & 3.72 \\
4 & 99.35 & 104.10 & 3.26 & 4.75 \\
5 & 99.38 & 104.18 & 1.95 & 4.80 \\
6 & 100.23 & 104.06 & 2.55 & 3.83 \\
7 & 98.60 & 102.23 & 2.19 & 3.63 \\
8 & 98.90 & 103.03 & 1.65 & 4.13 \\
\hline
\end{tabular}

Figure 3. The average compaction ratios measured by sand cone and nuclear method. Source: Self-elaboration.

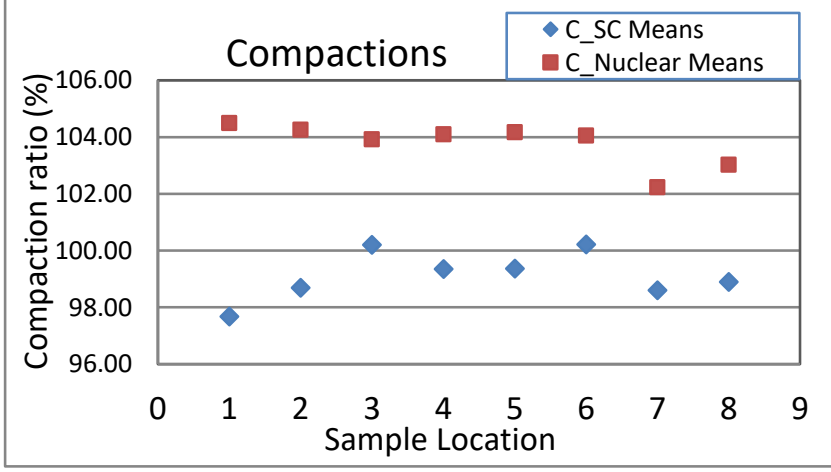




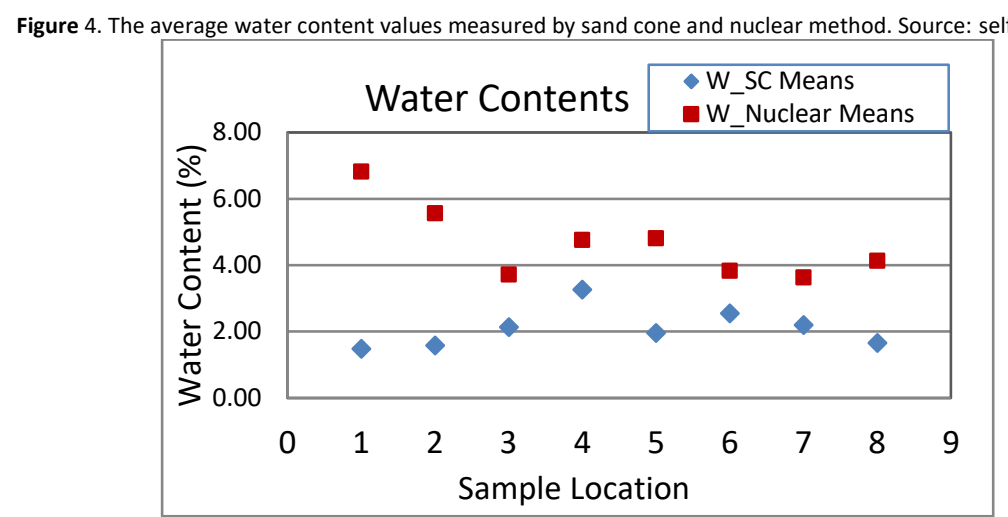

The descriptive statistics of each parameter were calculated for the evaluation of the test results. The Anderson-Darling test was applied to the data and Johnson transformation was used for nonnormal data. After all the data were transformed to normal distribution, variability and comparison tests were performed. In this context, the variance test was applied to determine the consistency of the test results. Correlation analysis was used to determine the consistency of the means and to determine the correlation between the variance analysis and the same kind of data. In addition, the central tendency and variability of the data were analyzed with the Box graph.

\section{Modelling of the Test Results}

The relationship between sand cone and nuclear method is modeled by statistical methods. Regression analysis and Artificial Neural Networks were used. An Artificial Neural Network (ANN) is a computational model based on the structure and functions of biological neural networks. Information that flows through the network affects the structure of the ANN because a neural network changes - or learns, in a sense - based on that input and output. ANNs are considered nonlinear statistical data modeling tools where the complex relationships between inputs and outputs are modeled or patterns are found (Technopedia). ANN acquires a large collection of units that are interconnected in some pattern to allow communication between the units. These units, also referred to as nodes or neurons, are simple processors which operate in parallel. Every neuron is connected with other neuron through a connection link. Each connection link is associated with a weight that has information about the input data. This is the most useful information for neurons to solve a particular problem because the weight usually increase or decrease the effect of data that is being communicated. Each neuron has an internal state, which is called activation. Output after combining the input data and activation rule the output may be obtained (Tutorialspoint).

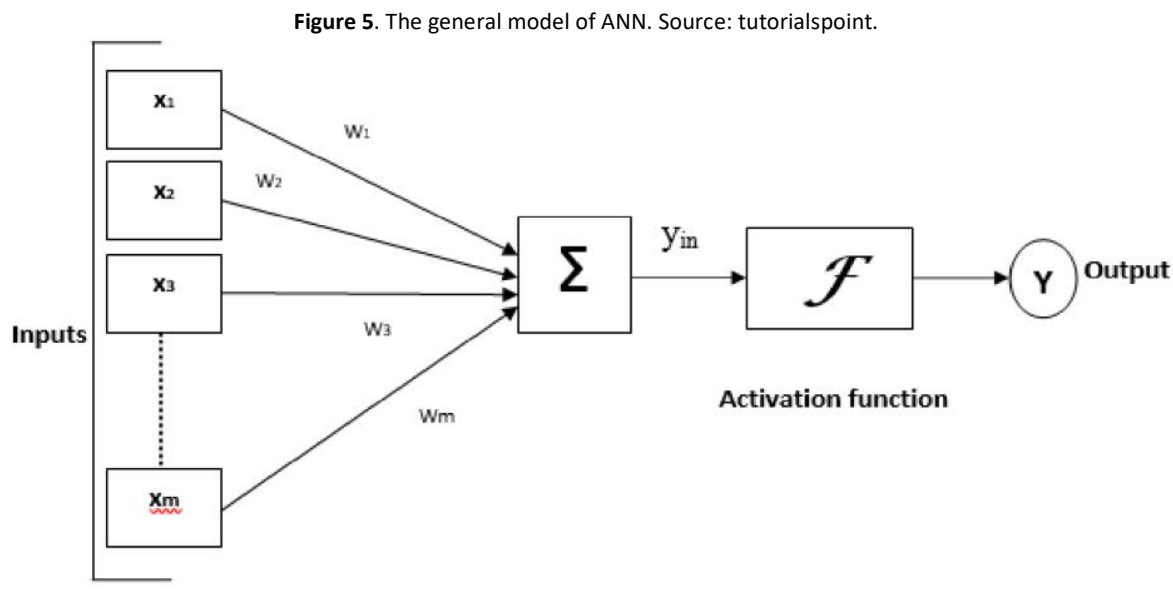

Conformity of the data to normal distribution was tested with the Anderson-Darling test (Table 2), and the water content values that were not suitable for normal distribution were normalized to Jonson Transformation (Figure 6). The statistical characteristics of all data with normalized data are given in Table 3. Correlations between the data are given in Table 4. In the tables and figures used abbreviations:

C_SC: Soil compaction values calculated by sand cone method,

C_N: Soil compaction values calculated by nuclear method, 
W_SC: Water content values calculated by sand cone method,

W_N: Water content values calculated by nuclear method,

W_SC_normalized: Transformed to normal distribution of water content values calculated by sand cone method, W_N_normalized: Transformed to normal distribution of water content values calculated by nuclear method.

Figure 6. Sand cone and nuclear methods of calculated computed soil compaction and Water Content values according to $95 \%$ confidence interval and Anderson-Darling $(A D)$ test results. Source: self-elaboration.

Normal - $95 \%$ CI
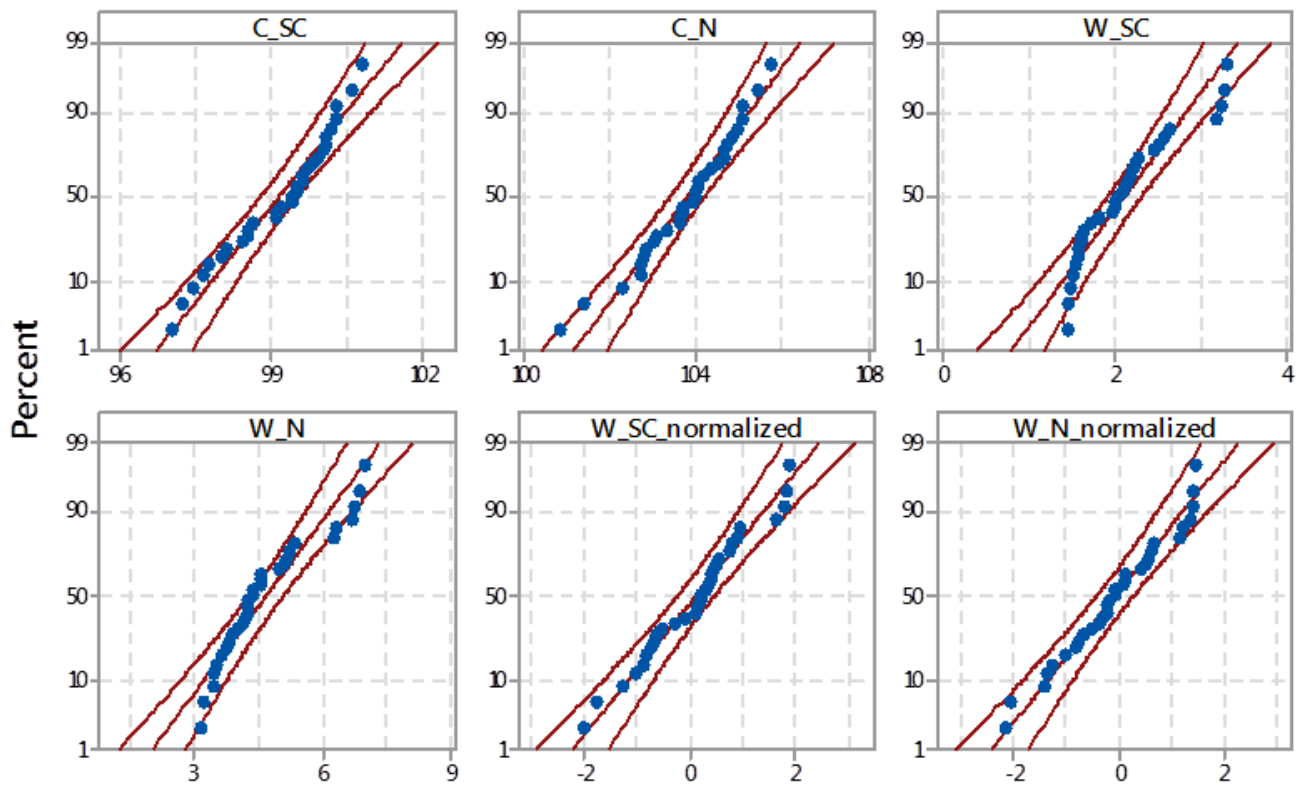

Table 2. Anderson-Darling (AD) test results. Source: self-elaboration.

\begin{tabular}{llll}
\hline Variable & $\begin{array}{l}\text { Test } \\
\text { statistics }\end{array}$ & $\begin{array}{l}\text { Significance } \\
\text { level }\end{array}$ & Distribution \\
\hline C_SC & 0.604 & 0.106 & Normal \\
C_N & 0.362 & 0.422 & Normal \\
W_SC & 1.011 & 0.001 & Non Normal \\
W_N & 1.073 & 0.007 & Non Normal \\
W_SC_normalized & 0.340 & 0.474 & Normal \\
W_N_normalized & 0.258 & 0.695 & Normal \\
\hline
\end{tabular}

Table 3. Statistical features of data. Source: self-elaboration.

\begin{tabular}{|c|c|c|c|c|c|c|c|c|c|c|}
\hline Variable & $\mathbf{z}$ & $\begin{array}{l}\stackrel{5}{\mathbb{J}} \\
\stackrel{\mathbb{N}}{\Sigma}\end{array}$ & 离 & $\begin{array}{l}\frac{n}{\frac{\pi}{\pi}} \\
\stackrel{\frac{\pi}{2}}{\frac{\pi}{\pi}}\end{array}$ & $\stackrel{\xi}{\bar{n}}$ & 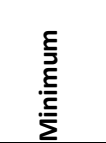 & $\begin{array}{l}\frac{\Sigma}{0} \\
\frac{0}{0} \\
\frac{d}{\Sigma}\end{array}$ & 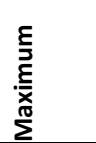 & 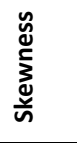 & $\begin{array}{l}\frac{n}{n} \\
\stackrel{t}{2} \\
\underline{x}\end{array}$ \\
\hline C_SC & 31 & 99.135 & 1.053 & 1.110 & 3073.200 & 97.000 & 99.400 & 100.80 & -0.51 & -0.76 \\
\hline $\mathrm{C} \_\mathrm{N}$ & 31 & 103.810 & 1.13 & 1.290 & 3217.990 & 100.820 & 103.970 & 105.75 & -0.70 & 0.54 \\
\hline W_SC & 31 & 2.112 & 0.568 & 0.323 & 65.460 & 1.440 & 2.020 & 3.320 & 0.87 & -0.04 \\
\hline W_N & 31 & 4.671 & 1.144 & 1.308 & 144.790 & 3.150 & 4.350 & 6.970 & 0.79 & -0.45 \\
\hline W_SC_normalized & 31 & 0.132 & 1.000 & 1.001 & 4.096 & -1.996 & 0.240 & 1.915 & -0.12 & -0.25 \\
\hline W_N_normalized & 31 & -0.082 & 1.006 & 1.012 & -2.530 & -2.155 & -0.106 & 1.486 & -0.20 & -0.53 \\
\hline
\end{tabular}

\begin{tabular}{lccc}
\multicolumn{4}{c}{ Table 4. Pearson correlation values Source: Self-elaboration. } \\
\hline & C_SC & C_N & W_SC_normalized \\
\hline C_N & 0.456 & & \\
p value & 0.010 & & \\
W_SC_normalized & 0.513 & -0.132 & \\
p value & 0.003 & 0.480 & -0.492 \\
W_N_normalized & -0.453 & 0.543 & 0.005 \\
p value & 0.011 & 0.002 &
\end{tabular}


It was determined with variance test that variances can be accepted as equal (Table 5). The variance analysis test, which assumes the equality of the variances, was investigated to determine if the means could be considered equal by applying the values of the soil compression values and the water content separately (Table 6).

\begin{tabular}{|c|c|c|c|c|c|c|c|c|c|}
\hline \multicolumn{5}{|c|}{ Ho: $\sigma\left(C_{-} S C\right) / \sigma\left(C_{-} N\right)=1$} & \multicolumn{5}{|c|}{ Ho: $\sigma($ W_SC_normalized $) / \sigma($ W_N_normalized $)=1$} \\
\hline \multirow{2}{*}{\multicolumn{5}{|c|}{$\begin{array}{l}\mathrm{H} 1: \sigma\left(C_{-} S C\right) / \sigma\left(C_{-} N\right) \neq 1 \\
\text { Significance level }: \alpha=0.05\end{array}$}} & \multicolumn{5}{|c|}{$\mathrm{H} 1: \sigma(\mathrm{W} S \mathrm{SC}$ normalized $) / \sigma\left(\mathrm{W} \_\mathrm{N}\right.$ normalized $) \neq 1$} \\
\hline & & & & & Significa & ince 1 & evel: & $\alpha=0.05$ & \\
\hline \multicolumn{5}{|c|}{ Ratio of variances $=0.862$} & \multicolumn{5}{|c|}{ Ratio of variances $=0.988$} \\
\hline Method & DF1 & DF2 & Statistics & $p$-value & Method & DF1 & DF2 & Statistics & $\mathrm{p}$-value \\
\hline Bonett & 1 & - & 0.16 & 0.691 & Bonett & 1 & - & 0.00 & 0.972 \\
\hline Levene & 1 & 60 & 0.01 & 0.914 & Levene & 1 & 60 & 0.02 & 0.877 \\
\hline
\end{tabular}

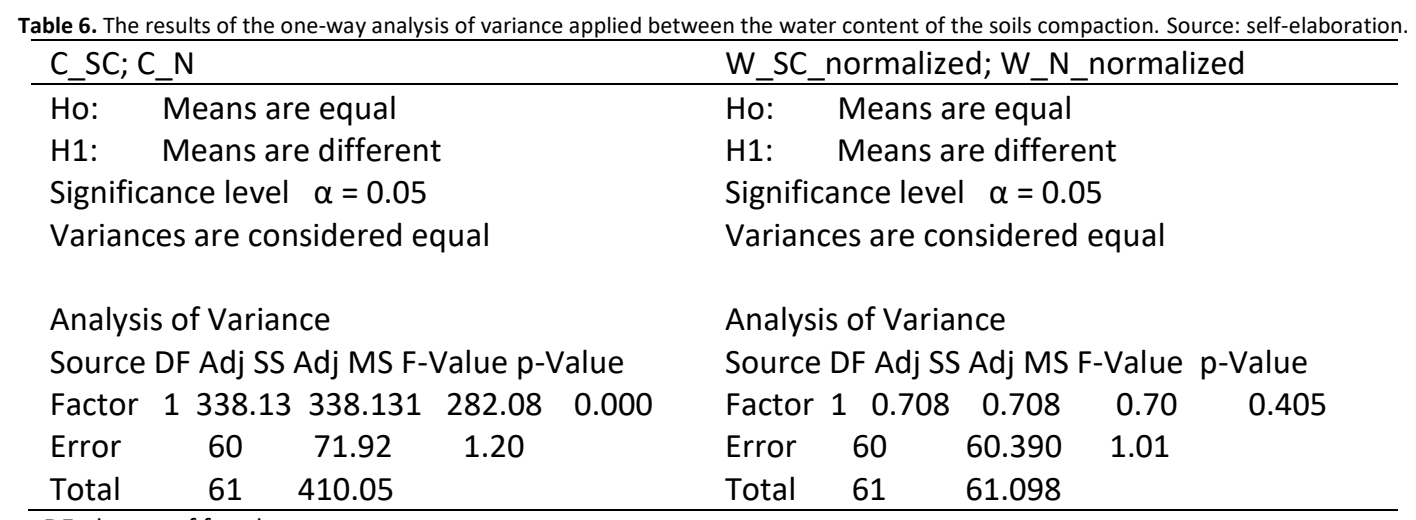

Figure 7 shows marginal and Box graph of compaction percentage found with sand cone (C_SC) and nuclear test, Figure 8 shows marginal and box graph of normalized water content found with sand cone (W_SC normalized) and nuclear (W_N normalized) methods.

Figure 7. Margin and box-whisker graph of soil compaction ratios found by sand cone (C_SC) and nuclear (C_N) method. Source: self-elaboration.

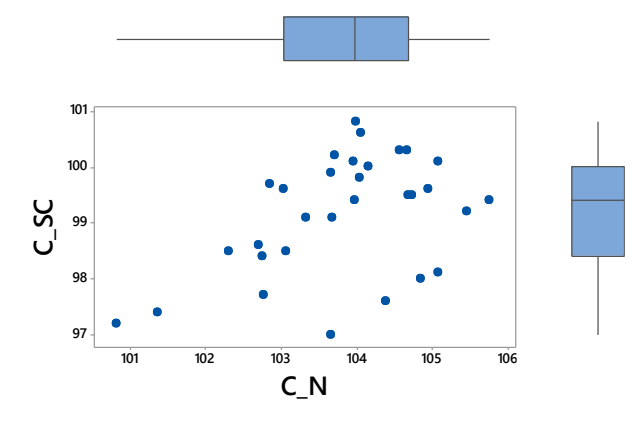

Figure 8. Marginal and box-whisker graph of normalized water content percentages found with the Nuclear (W_N_normalized) and Sand Cone (W_SC_normalized) methods. Source: self-elaboration.

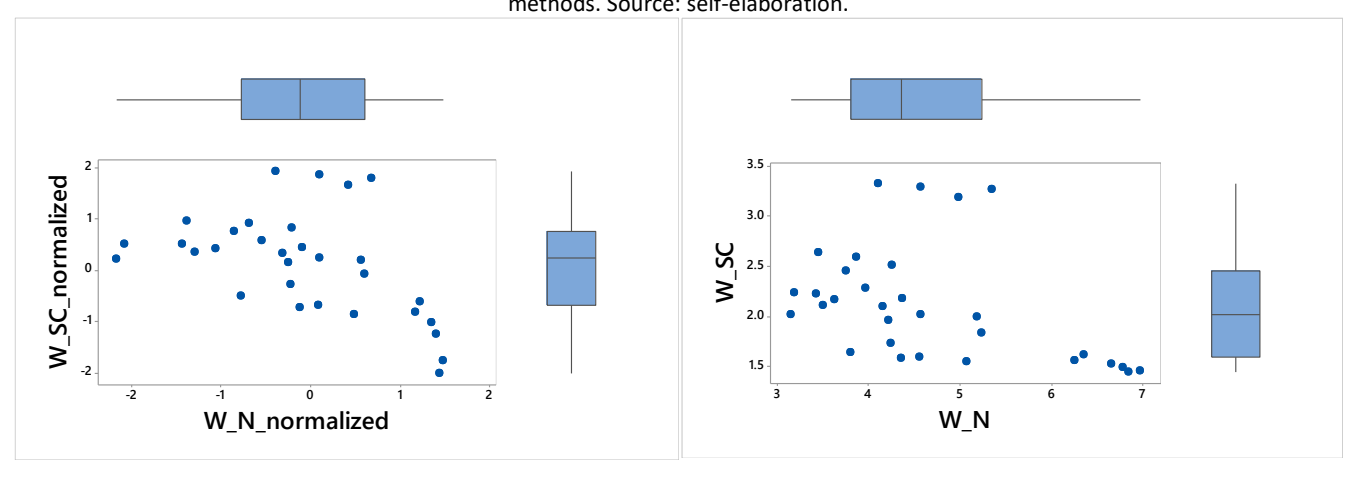




\section{Analysis of Regression}

1, 2 and 3-degree polynomial regression were investigated. The consistency of regression models was tested by variance analysis. The models obtained as a result of regression analysis are given in Table 7.

Table 7. Regression analysis results. Source: self-elaboration.

\begin{tabular}{lllc}
\hline & Regression Analysis & R & Significance level \\
\hline 1 & C_SC $=55.2+0.423$ C_N & $20.8 \%$ & 0.010 \\
2 & C_SC $=-2020+40.56$ C_N -0.1940 C_N^2 & $30.7 \%$ & 0.006 \\
3 & C_SC $=51572-1516$ C_N +14.88 C_N^2 - 0.04863 C_N^3 & $31.8 \%$ & 0.015 \\
4 & W_SC_normalized $=0.092-0.489$ W_N_normalized & $24.2 \%$ & 0.005 \\
& W_SC_normalized $=0.4416-0.61741 .091$ W_N_normalized -0.3648 & $41.8 \%$ & 0.001 \\
& W_N_normalized ^2 & \\
W_SC_normalized $=0.5599-0.1738$ W_N_normalized - 0.5392 & $46.7 \%$ & 0.001 \\
\hline
\end{tabular}

C_SC: Soil compaction value calculated by sand cone, C_N: Soil compaction value calculated by nuclear method, W_SC: Water content calculated by sand cone test, $\mathbf{W} \mathbf{N}$ : Water calculated by nuclear method

Figure 9-14 shows the graphical representation of linear, quadratic and cubic regression models investigated for soil compaction ratio and water content values calculated by sand cone and nuclear method. In the models, the values calculated by sand cone method were used as estimated, the values calculated by the nuclear method were used as estimators.

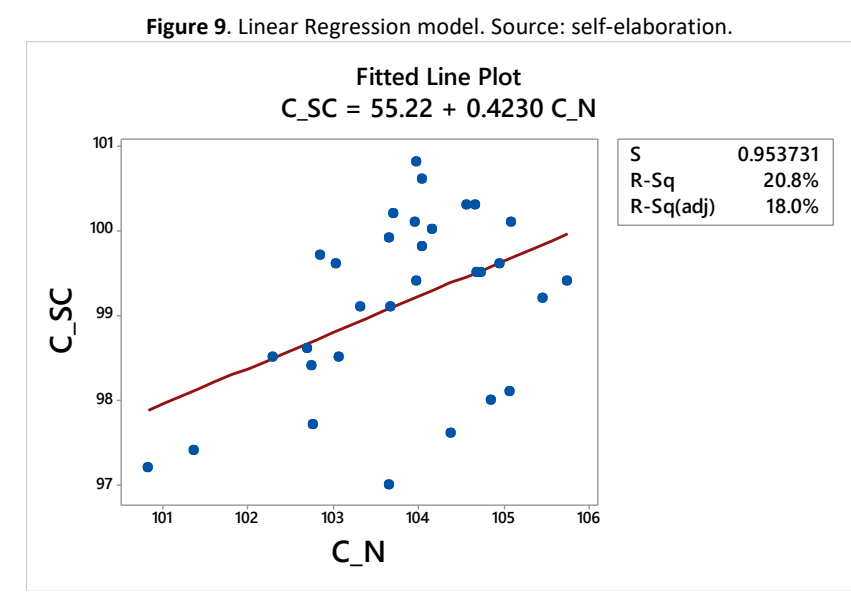

Figure 10. Linear Regression model for water content. Source: self-elaboration.

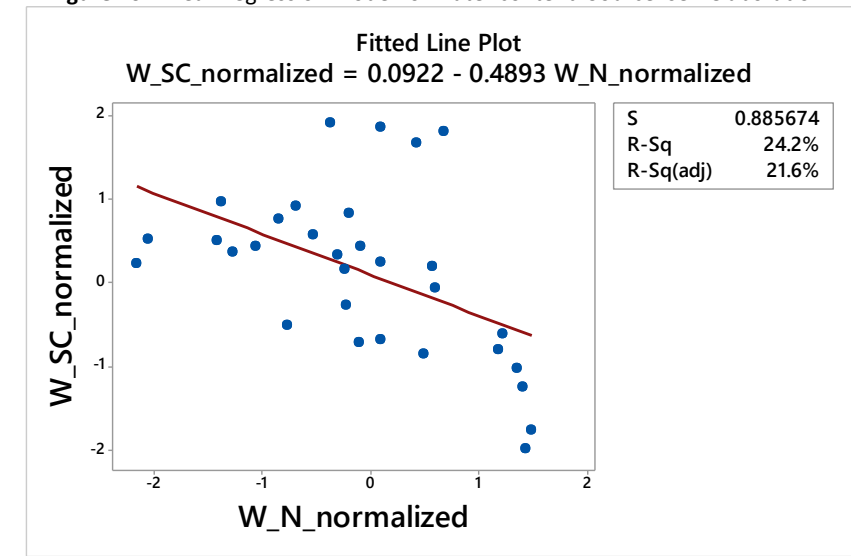


Figure 11. 2nd degree Polynomial Regression model for estimation of soil unit weight. Source: self-elaboration.

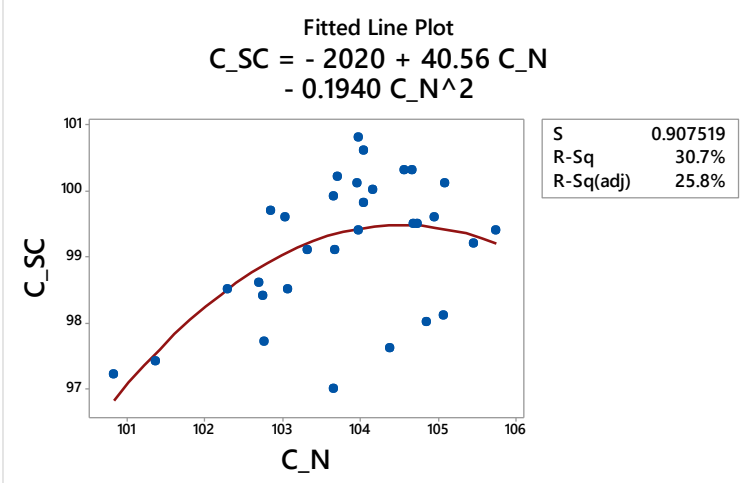

Figure 12. 2nd degree polynomial regression model for estimation of water content. Source: self-elaboration.

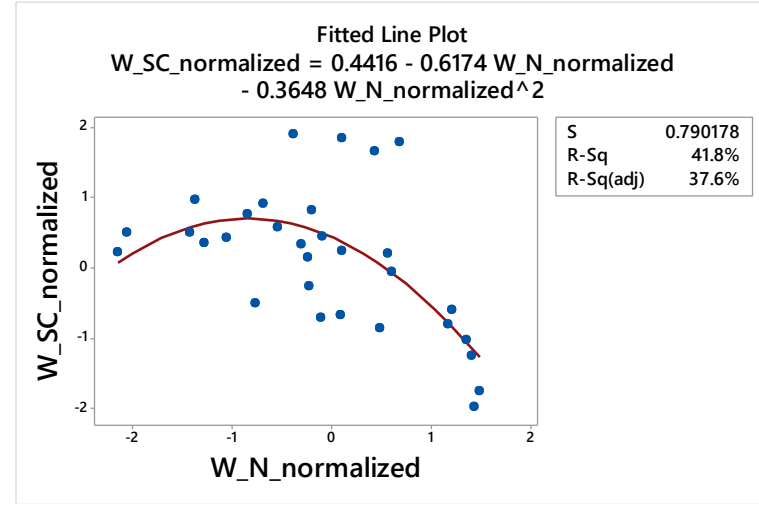

Figure 13. 3rd degree polynomial regression model for estimation of soil density. Source: self-elaboration.

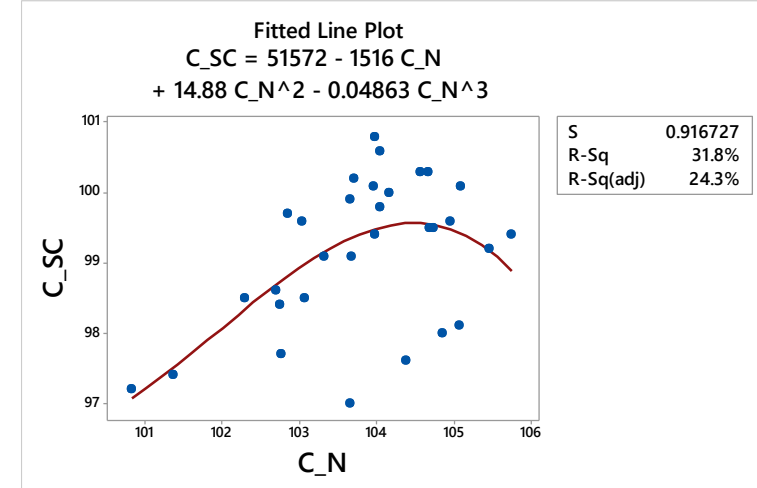

Figure 14. 3rd degree polynomial regression model for estimation of water content. Source: self-elaboration. Fitted Line Plot

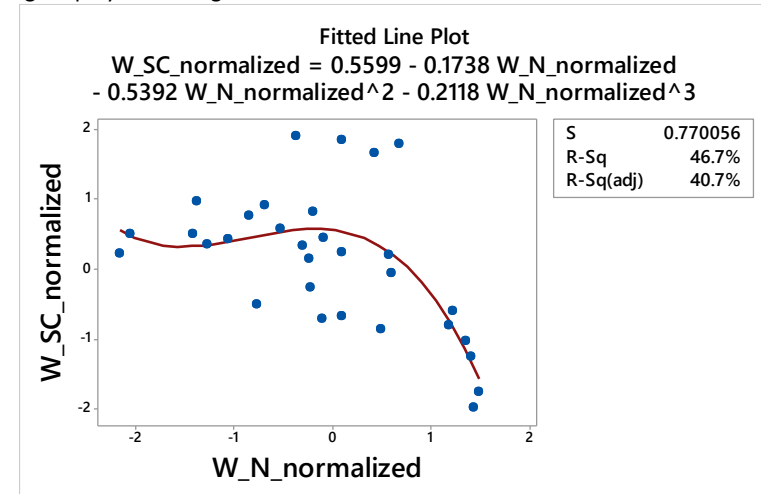




\section{Artificial Neural Network}

For the ANN analysis, the compaction ratio and the water content values found by the nuclear method were used separately and together as the input variable (predictive variable). The compaction ratio and the water content values calculated by sand cone method were modeled separately as output value (estimated). $70 \%$ of the data were used for Training, 15\% for Validation and 15\% for the Test. Hidden layer number 10 was selected. Levenberg-Marquardt training algorithm was selected. The results obtained at the end of the modeling study are given in Figure 15-18 and the performances of the models are given in Table 8.

\begin{tabular}{|c|c|c|c|c|c|c|c|c|}
\hline \multirow{2}{*}{\multicolumn{2}{|c|}{ Input }} & \multirow{3}{*}{$\begin{array}{l}\text { Output } \\
\text { Sand Cone } \\
\text { Compaction }\end{array}$} & \multicolumn{2}{|c|}{ Training } & \multicolumn{2}{|c|}{ Validation } & \multicolumn{2}{|c|}{ Testing } \\
\hline & & & MSE & $\mathrm{R}$ & MSE & $\mathrm{R}$ & MSE & $\mathrm{R}$ \\
\hline $\begin{array}{l}\text { Nuclear } \\
\text { Method } \\
\text { Compaction }\end{array}$ & & & 0.636 & 0.686 & 0.576 & 0.899 & 0.175 & 0.753 \\
\hline \multirow[t]{2}{*}{$\begin{array}{l}\text { Nuclear } \\
\text { Method } \\
\text { Compaction }\end{array}$} & $\begin{array}{l}\text { Nuclear } \\
\text { Method } \\
\text { Water } \\
\text { Content }\end{array}$ & $\begin{array}{l}\text { Sand Cone } \\
\text { Compaction }\end{array}$ & 0.000 & 1.000 & 0.025 & 0.997 & 0.057 & 0.955 \\
\hline & $\begin{array}{l}\text { Nuclear } \\
\text { Method } \\
\text { Water } \\
\text { Content }\end{array}$ & $\begin{array}{l}\text { Sand Cone } \\
\text { Water } \\
\text { Content }\end{array}$ & 0.256 & 0.616 & 0.037 & 0.840 & 0.015 & 0.923 \\
\hline $\begin{array}{l}\text { Nuclear } \\
\text { Method } \\
\text { Compaction }\end{array}$ & $\begin{array}{l}\text { Nuclear } \\
\text { Method } \\
\text { Water } \\
\text { Content }\end{array}$ & $\begin{array}{l}\text { Sand Cone } \\
\text { Water } \\
\text { Content }\end{array}$ & 0.176 & 0.719 & 0.040 & 0.880 & 0.209 & 0.903 \\
\hline
\end{tabular}

MSE : Mean Squared Error, R : Correlation coefficient

Figure 15. The compaction ratio calculated by the nuclear method is modeled as input, compaction ratio calculated by the sand cone method is modeled as output. Source: self-elaboration.
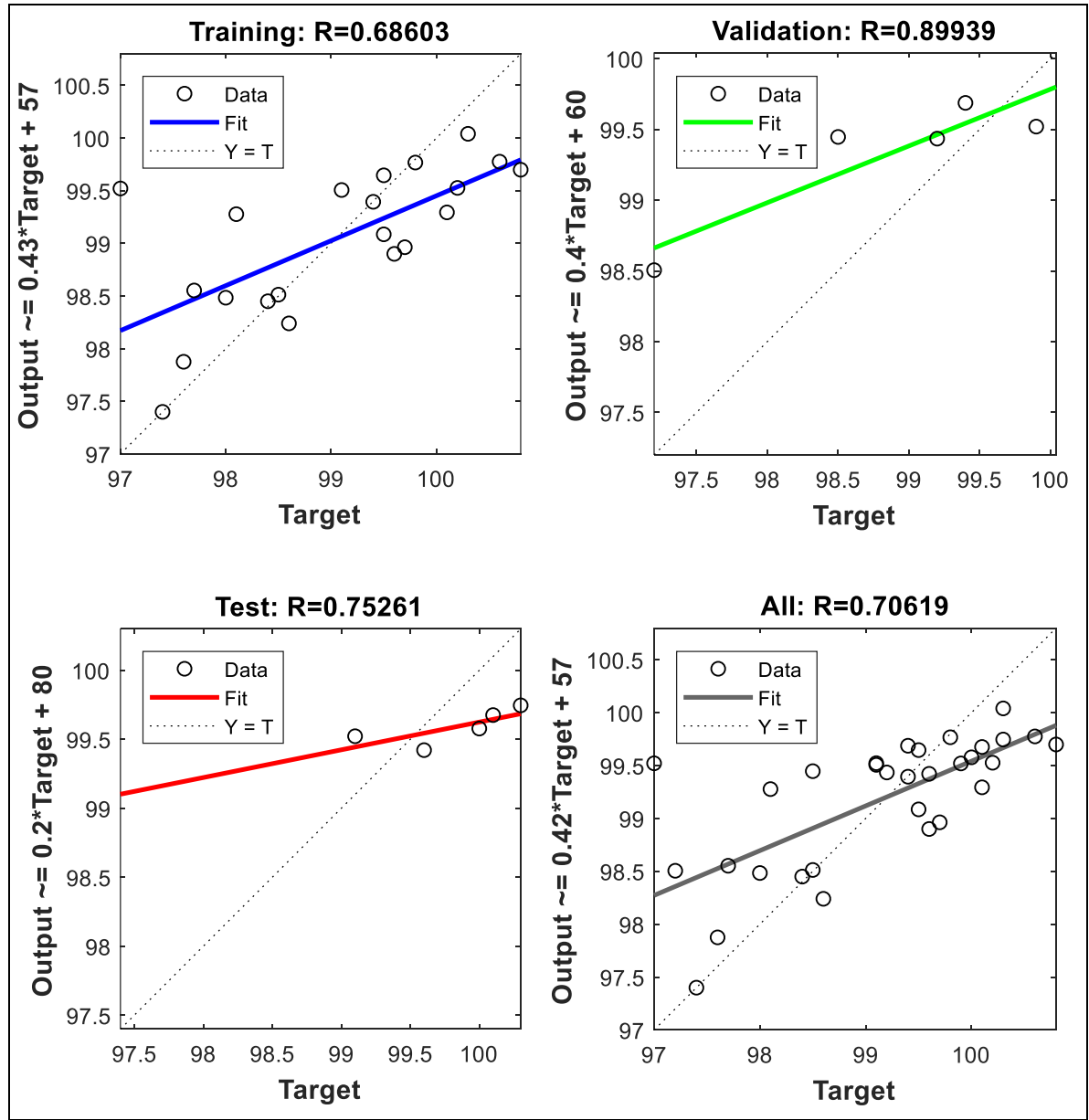
Figure 16. Water content calculated by the nuclear method is modeled as input, water content calculated by the sand cone method is modeled as output. Source: selfelaboration.
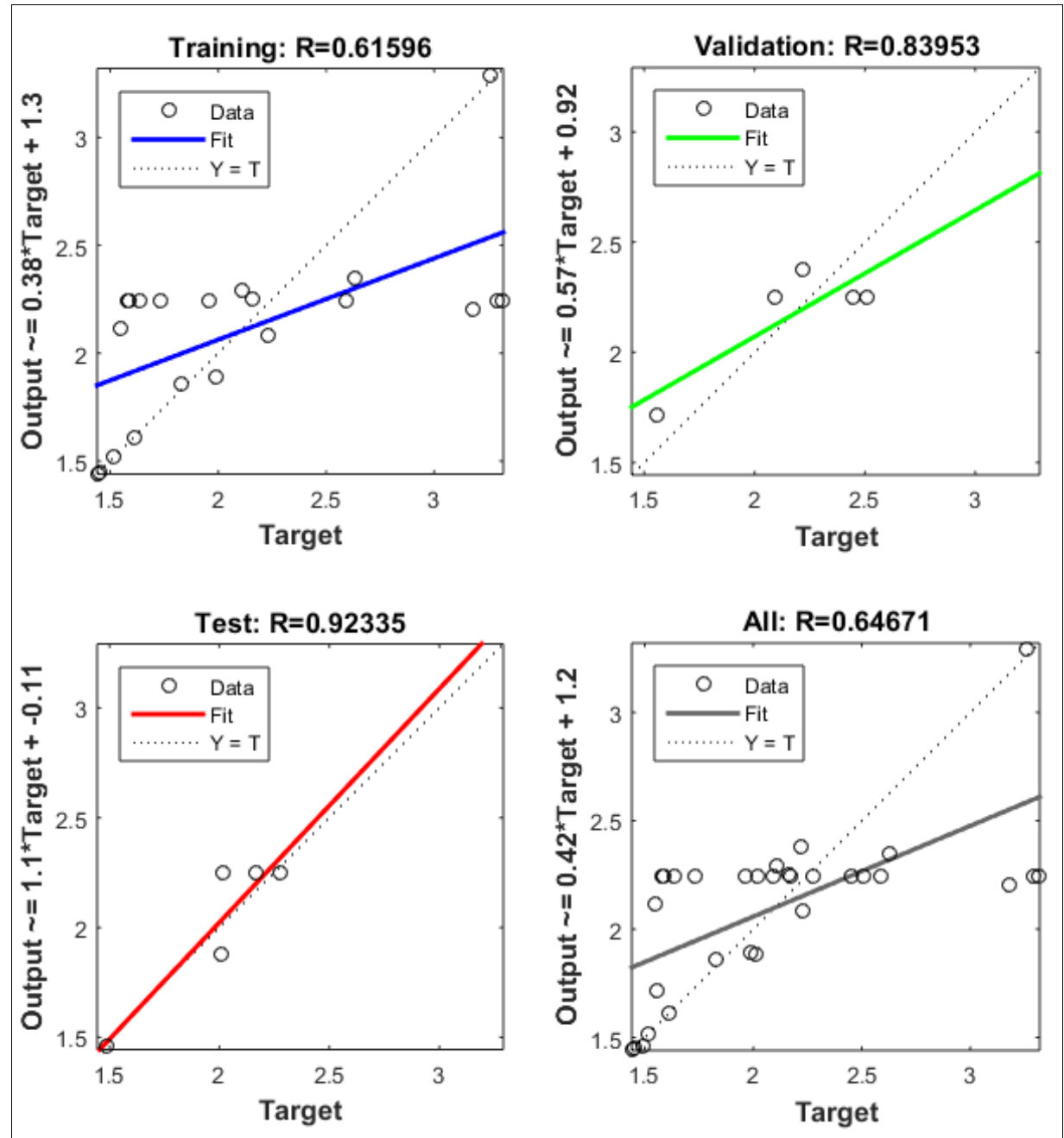

Figure 17. Water content and compaction ratio calculated by the nuclear method are modeled as input. compaction ratio calculated by the sand cone method is modeled as output. Source: self-elaboration.
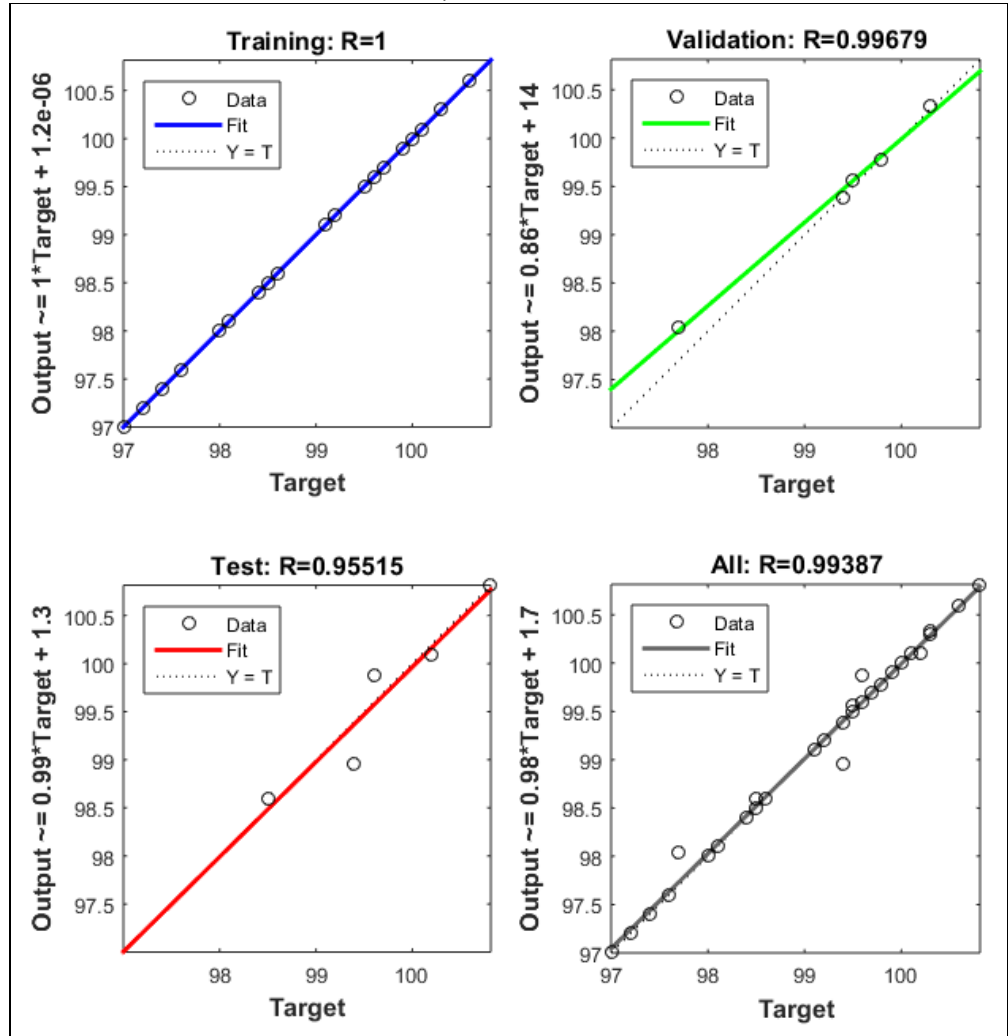
Figure18. Water content and compaction ratio calculated by the nuclear method are modeled as input, Water content calculated by the sand cone method is modeled as output. Source: self-elaboration.
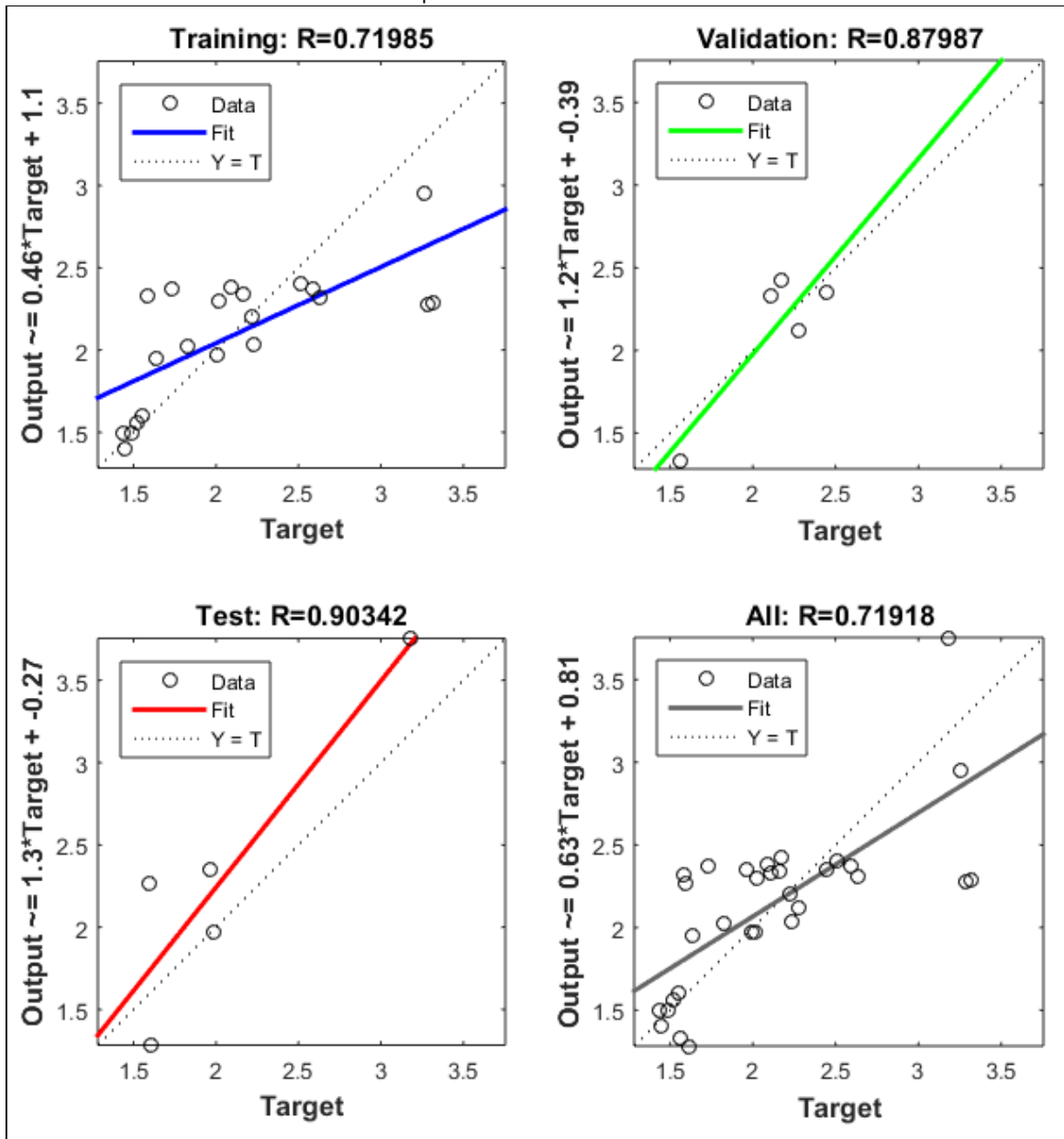

Discussion and Conclusions

According to variances in the table 2, the values of soil compaction and water content calculated by nuclear method are more variable, too many variabilities, it can be evaluated as less consistent. The variability in sand cone and nuclear methods can also be seen in Box-Whisker graphics (Figures 6 and 7). Both compaction ratio and water content values of nuclear method are larger than the values calculated by the sand cone method. As shown in Table 4, the correlation is low but statistically significant, although the correlation is expected to be high, it is evaluated that this low value originated from much variability in the data (especially in results of nuclear method). According to the Test of Variance Analysis from Table 5, the mean of compaction ratios in the sand cone and the nuclear methods is different, the mean of water content values are same in terms of statistic.

Since the averages of the compaction ratio values are statistically different and the correlation is low but meaningful, uncertainty arises as to which of the values found by the sand cone and nuclear method will be correct and will be used in the calculations. However, sand cone test gives more reliable results than nuclear tests (Altun et al., 2007; Altun et al., 2008). For this reason, it can be recommended to use the sand cone method in the determination of compaction. However, the nuclear method can be preferred because it gives rapid results. For this purpose, between the results obtained by the nuclear method and the results obtained by the sand cone method was developed a statistical model to be able to predict the results of the sand cone. Polynomial Regression Analysis and Artificial Neural Networks were used in the model studies. Although the Regression Models given in Table 7 are statistically significant, the correlations are low. In the modeling of Artificial Neural Networks (ANN), it is seen that the models found with ANN are more successful than the regression models. The results of these models are shown in Figure 15-18 and the performance summary of ANN models is given in Table 8.

ANN models which compaction ratio and water content values calculated by the nuclear method are used as estimator provide very successful results. Especially, the model where the soil compaction found by sand cone was tried to be estimated have worked successfully close to $100 \%$ (Table 8 ). In this regard, it is appropriate to develop a parameter such 
as standard or correction coefficient by making a detailed analysis for different soil types. Due to the statistical equality of the means, it can be said that there is no method difference in determining the water content values. However, the results obtained by the nuclear method are more variable than the sand cone method. The variability range in positive and negative directions according to the mean is about $10 \%$ (Table 3 ). In this case, the results obtained by the nuclear method may be $5 \%$ more or less than the average. According to this situation, $5 \%$ uncertainty arises in terms of technical and experimental cost. For this reason, it may be useful to consider that the variability may be high in the nuclear method test results. Therefore, it should not to be satisfied with one (or a few) test results in order to eliminate the negative effects that may be caused by experimental data and to check the consistency of the results with additional experiments.

\section{References}

Altun, S., Goktepe, A.B., Sezer, A., \& Okur, V. (2007). Control of Compaction Parameters of Compressed Road Soils. 2. Geotechnical Symposium, Adana, Turkey. 407-408.

Altun, S., Goktepe, A.B., \& Sezer, A. (2008). Investigation of Parameters of Compaction Testing. Turkish J Eng Env Sci. 32, 201-209.

ASTM D6938-17a. (2003), Standard Test Methods for In-Place Density and Water Content of Soil and Soil-Aggregate by Nuclear Methods (Shallow Depth), Annual Book of ASTM Standards.

Chai, J.L.; \& Wang, Y. (2014). The Application research of Non-nuclear density gauge electromagnetic technology in the road engineering. Appl Mech and Materials. 597,384-387.

Chanyong, C.; Minwoo, S.; Daehyeon K, \& Xiong Y. (2016). A New Non-Destructive TDR System Combined with a Piezoelectric Stack for Measuring Properties of Geomaterials. Materials. 9(6):439.

EPA United States Environmental Protection Agency, (2019, 23 April). Nuclear Gauges. https://www.epa.gov/radtown/nuclear-gauges

Hassanlourad, M.; Ardakani, A.; Kordnaeij, A.; \& Mola-Abasi, H. (2017). Dry unit weight of compacted soils prediction using GMDH-type neural network. Eur Phys J Plus. 132, 357.

Ground Engineering Service, (2019, 23 April). Sand Cone Test. http://zeminteknolojileri.com/en/activity.asp?p=66\&q=45

Sawangsuriya, A.; Ketkaew, C.; \& Sramoon, W. (2012). Laboratory Evaluation of the Soil Density Gauge (SDG). GeoCongress 2012 C ASCE. $2707-2715$.

TS 1900-1: (2006). Methods of testing soils for civil engineering purposes in the laboratory - Part 1: Determination of physical properties. (Turkish Standard).

Technopedia, (2019, May 19). Artificial Neural Network (ANN). https://www.techopedia.com/definition/5967/artificial-neural-network-ann

Tutorialspoint, (2019, May 19). Artificial Neural Network Tutorial. https://www.tutorialspoint.com/artificial_neural_network/ 